\title{
PRESENÇA JESUÍTICA NA VILA DE PARANAGUÁ: O PROCESSO DE ESTABELECIMENTO DO COLÉGIO JESUÍTICO (1708-1759).
}

\author{
Meiri Cristina Falcioni Malvezzi*
}

RUCKSTADTER, Vanessa Campos Mariano. Presença jesuítica na Vila de Paranaguá: o processo de estabelecimento do Colégio Jesuítico (1708-1759). Maringá: EDUEM, 2011. 125 p.

Palavras-chave: História da Educação Brasileira; Período Colonial; Colégio dos Padres Jesuítas em Paranaguá.

Os estudos sobre a atuação pedagógica dos padres da Companhia de Jesus no Brasil Colonial ganham um novo impulso com a contribuição da pesquisadora Vanessa Campos Mariano Ruckstadter e seu livro Presença jesuítica na Vila de Paranaguá: o processo de estabelecimento do Colégio Jesuítico (1708-1759). A obra apresenta e analisa documentos inéditos a respeito da fundação do Colégio Jesuítico na Vila de Nossa Senhora do Rosário de Paranaguá, no ano de 1755. Publicado pela EDUEM, o livro foi inicialmente uma dissertação de mestrado defendida junto ao Programa de Pós-Graduação em Educação da Universidade Estadual de Maringá, sob a orientação do professor Doutor Cézar de Alencar Arnaut de Toledo. A autora participa do Grupo de Pesquisa sobre

* Possui graduação em Pedagogia (2010) e Mestrado em Educação (2012), pela Universidade Estadual de Maringá. Doutoranda em Educação pela mesma Instituição (2015-2018). Tem experiência na área de Educação, atuando principalmente nos seguintes temas: Educação Brasileira, História da Educação, Legislação Educacional. Exerce a função de Pedagoga na Secretaria de Estado do Trabalho e Desenvolvimento Social (SEDS/PR). 
Política, Religião e Educação nos Tempos Modernos, no qual desenvolve a linha de pesquisa Os jesuítas e a formação da cultura brasileira. Ela é licenciada em História pela Universidade Estadual de Maringá e atualmente é professora no Departamento de Educação da Universidade Estadual de Londrina.

A escassez de fontes e o fato de o Colégio jesuítico de Paranaguá ser o menos citado na historiografia, se comparado aos demais colégios jesuíticos, levaram a autora a uma exaustiva pesquisa sobre a história do estabelecimento deste colégio em um território que pertencia à Capitania e depois Província de São Paulo, até dezembro de 1853, e que atualmente pertence ao Estado do Paraná.

A obra está organizada em três capítulos, nos quais dois questionamentos centrais perpassam as discussões: "O primeiro deles é o motivo que teria levado os moradores da Vila de Paranaguá a reivindicarem a fundação de um colégio jesuítico na região [...]. A segunda indagação é ligada ao longo processo de estabelecimento do Colégio Jesuítico de Paranaguá" (p. 20).

No primeiro capítulo, intitulado Fontes e Pesquisas para o estudo da presença jesuítica na Vila de Paranaguá, a autora fala da busca de fontes primárias, bem como do processo de seleção de manuais de História da Educação, História do Brasil e História do Paraná para a realização da pesquisa. A constatação de que existe uma lacuna na historiografia referente à presença dos padres da Companhia de Jesus em Paranaguá direcionou a pesquisa para a utilização, principalmente, de fontes primárias.

Após uma exaustiva busca de fontes em arquivos do Brasil e de Portugal, pelas bases de dados disponíveis na rede mundial de computadores, foram encontrados importantes documentos no Arquivo Público do Estado de São Paulo. O resultado da seleção de material, priorizando fontes primárias, está registrado nos anexos, nos quais constam fotos de documentos referentes à Câmara de Paranaguá, datados de meados dos séculos XVII e XVIII.

De posse desses documentos, as análises foram desenvolvidas com base no reconhecimento de que "[...] o documento é sempre portador de um discurso. Sempre envolto em uma carga ideológica" (p. 21). Partindo desse pressuposto, a autora afirma que a análise do Colégio de Paranaguá deve ser inserida numa ampla rede 
de relações políticas e econômicas para que se possa explicar os fatos e documentos referentes a ele.

A atuação da Companhia de Jesus no Brasil é o título do segundo capítulo do livro. Foi feito um recuo para contextualizar a fundação, em 1539, da Companhia de Jesus e a atuação dos padres jesuítas nos colégios por eles fundados na Europa e, mais especificamente, no Brasil Colonial. O livro discute a característica missionária da Ordem religiosa, desde a chegada dos primeiros padres no ano de 1549, como forte aliada da Coroa Portuguesa "[...] em torno de objetivos comuns: colonizar as novas terras, levando aos nativos a 'civilização' europeia, seus costumes e seu Deus” (p. 51). A contraposição entre aculturação e dominação dos índios brasileiros é analisada para além do contexto religioso, passando pela perspectiva econômica da expansão do capitalismo comercial no Novo Mundo.

A autora aponta algumas características que diferem as casas jesuíticas dos colégios e seminários jesuíticos implantados no Brasil, no que se referem aos objetivos desses estabelecimentos. Diferentemente das casas jesuíticas e dos seminários, cujos objetivos eram, no primeiro caso, o ensino das primeiras letras aos índios e a catequese, e no segundo, a instrução daqueles que tinham interesse na vida eclesiástica, os colégios jesuíticos tinham como objetivo atender aos filhos dos colonos. Outra característica dos colégios diz respeito ao caráter econômico. A fundação de um colégio jesuítico só era permitida pela Coroa Portuguesa se "[...] pudesse se manter com posses próprias" (p. 55).

Sobre a administração dos bens dos padres jesuítas, no capítulo intitulado A atuação jesuítica na Vila de Paranaguá, a autora apresenta documentos, alguns inéditos, que possibilitam uma análise da atuação dos padres inacianos não somente como missionários, mas também como zelosos homens de negócios. Ela destaca que a importância política, econômica e cultural da Vila de Paranaguá, durante o período Colonial, devido à localização estratégica para o governo português, foi determinante para a fundação de um colégio jesuítico na Vila. A presença dos padres jesuítas na região, no período entre 1708 a 1759 , supria a necessidade dos moradores, a maioria analfabetos, de acesso à "[...] cultura letrada pelo argumento da necessidade da religião e dos sacramentos" (p. 78). 
O recorte estabelecido para a discussão sobre a atuação dos padres jesuítas na Vila de Paranaguá, entre os anos de 1708 e 1759, não provocou um engessamento na busca e na seleção das fontes consultadas. A autora apresenta, como primeira iniciativa das autoridades locais para a fundação do Colégio Jesuítico, uma carta da Câmara de Paranaguá, endereçada ao Padre Geral da Companhia, do ano de 1682, solicitando a instalação de uma Casa Jesuítica na Vila. O pedido foi reiterado, por meio de outra carta, no ano de 1685, mas, não foi atendido por Roma, devido à "[...] falta de recursos financeiros e garantias de subsistência para os padres jesuítas" (p. 79). A autora aponta que, nos anos de 1707 e 1708, a questão foi resolvida pelos moradores da Vila, bem como pela Câmara Municipal, que doaram, entre outros bens, metade de uma ilha, cabeças de gado, terras para a implantação de um colégio jesuítico e "[...] bens materiais para o funcionamento de uma fazenda a fim de sustentar o Colégio em Paranaguá" (p. 80). No ano de 1708, foi estabelecida uma Casa jesuítica em Paranaguá, instituindo-se também um Seminário na Vila, a fim de formar padres para a Ordem.

Desde a instalação da Casa até a fundação do Colégio "[...] um longo e lento processo burocrático ocorreu" (p. 82). Para a análise desse processo, a autora se debruçou sobre os documentos contidos na obra clássica de Serafim Leite, História da Companhia de Jesus no Brasil, e nos documentos encontrados no Arquivo Público do Estado de São Paulo. Esses documentos revelam um conflito que se instaurou entre a Câmara de Paranaguá e os padres jesuítas, decorrente das doações recebidas para a instalação da Casa Jesuítica e, posteriormente do Colégio. Entre os documentos analisados pela autora estão uma Representação da Câmara de Paranaguá, escrita no ano de 1722, solicitando ao Rei de Portugal a permissão para o funcionamento do Colégio, e outra Representação da Câmara de Paranaguá, datada de 1743, acusando os padres de terem avançado para além das terras doadas para a construção do Colégio. Contudo, o Colégio foi fundado no ano de 1755.

$\mathrm{Na}$ análise da pesquisadora, a duração de quase meio século para o trâmite do processo que pretendia estabelecer o Colégio em Paranaguá pode ser justificada pelo "[...] próprio sistema burocrático português implantado na Colônia" (p. 106). Se, por um lado, a presença desses missionários representava prestígio à Vila, por outro, 
as autoridades temiam que a Ordem religiosa enriquecesse com as doações recebidas para a fundação do Colégio. O enriquecimento dos padres jesuítas é um dos fatores que contribuiu para a expulsão da Ordem das terras portuguesas em 1759.

Desde 1972, o prédio que fora o antigo Colégio Jesuítico em Paranaguá passou a fazer parte do Patrimônio Histórico e Artístico Nacional. Nele funciona o Museu de Arqueologia e Artes Populares da Universidade Federal do Paraná, dividido em dois setores: o Setor de Arqueologia e o Setor de Artesanato. A autora destaca que "[...] não há no museu referência à atuação dos padres jesuítas, bem como não há documentos referentes ao colégio. A referência feita em visitas ao museu se restringe ao fato dele ter sido um Colégio Jesuítico" (p. 73).

Ao concluir pela importância que se reveste a obra Presença jesuítica na Vila de Paranaguá: o processo de estabelecimento do Colégio Jesuítico (1708-1759), fica evidenciado que o estudo sobre a atuação pedagógica dos padres da Companhia de Jesus não está esgotado. Algumas considerações devem ser feitas quanto à escassez de estudos sobre a atuação dos jesuítas em Paranaguá, mais especificamente sobre a fundação e o funcionamento do colégio. $\mathrm{O}$ fato do Colégio Jesuítico de Paranaguá ter existido por um período curto (1755-1759), muitas vezes, é apresentado como justificativa para a lacuna existente sobre essa temática nos manuais de História do Brasil, bem como nos manuais de História do Paraná. Outra justificativa diz respeito à ausência de fontes disponíveis no Estado do Paraná, sobretudo no Arquivo do Estado do Paraná e no Instituto Histórico e Geográfico de Paranaguá, fator que dificulta e desestimula a pesquisa sobre a história da educação regional.

Contudo, esses fatores não foram suficientes para conter o anseio de Vanessa Campos Mariano Ruckstadter para descobrir novas fontes e responder aos questionamentos que a motivaram durante a pesquisa. O resultado do trabalho de pesquisa sobre a fundação do Colégio Jesuítico de Paranaguá aponta novas possibilidades de discussões. Novas fontes podem ser encontradas e novos trabalhos podem ser realizados, diminuindo, assim, a lacuna na historiografia referente à presença dos padres da Companhia de Jesus em Paranaguá, bem como sobre a atuação desses educadores no âmbito 
educacional em geral. O texto tem uma linguagem objetiva e acessível e é recomendado aos pesquisadores interessados no tema.

RECEBIDA EM: 17/10/2015

APROVADA EM: 16/02/2015 